\title{
Relay Synthesis of Azadirachtin
}

\section{Key words}

\section{Claisen}

rearrangement

radical cyclization

peroxidation

allenes

SYNFACTinth

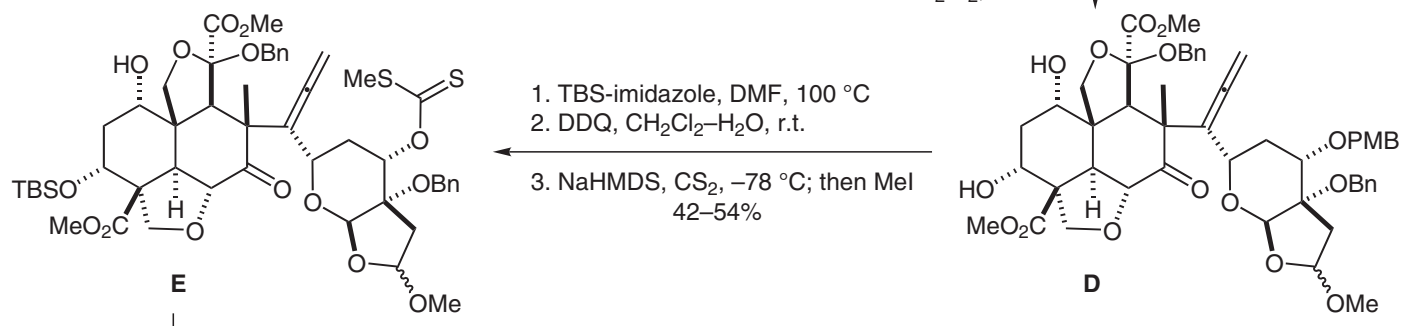

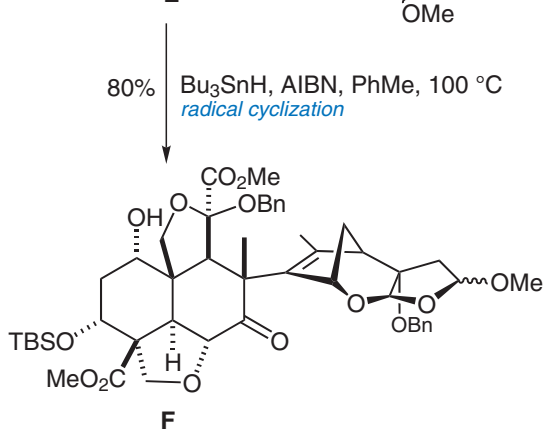<smiles>Cc1cc(O)c(Br)cc1Sc1cc(Br)c(Br)cc1C</smiles>

MMPP. $\mathrm{H}_{2} \mathrm{O}, \mathrm{NaHCO}_{3}$ $\mathrm{MeOH}$ (sealed tube)
$105^{\circ} \mathrm{C}, 7 \mathrm{~d}$ $20 \%(85 \%$ brsm $)$ MMPP = magnesium monoperoxyphthalic acid

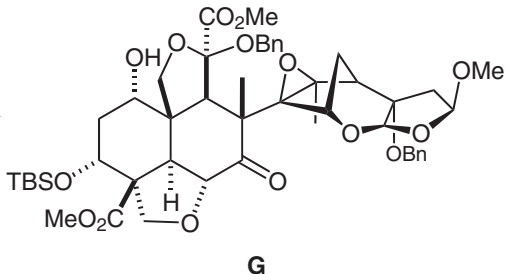

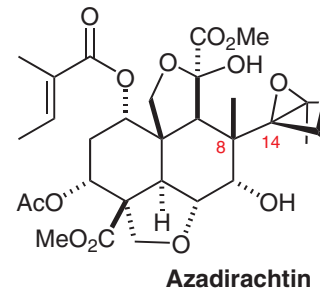

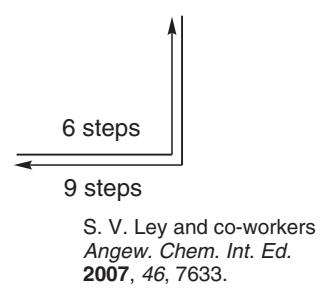

Significance: Azadirachtin is an insect antifeedant. A major challenge in this 22-year odyssey was the construction of 16 contiguous stereogenic centers seven of which are quaternary. The excerpt depicted here focuses on the Claisen rearrangment used to construct the congested C8C14 bond.
Comment: Compounds $\mathbf{A}$ and $\mathbf{G}$ were obtained by total synthesis and by degradation of azadirachtin. The degradation route enabled exploration of the difficult closing stages of the synthesis. Note the harsh conditions required to effect the difficult epoxidation $\mathbf{F} \rightarrow \mathbf{G}$.

SYNFACTS Contributors: Philip Kocienski

Synfacts 2008, 2, 0111-0111 Published online: 23.01.2008 Dol: 10.1055/s-2007-992496; Reg-No.: K16707SF 